\title{
Global sourcing risk management approaches: A study of small clothing and textile retailers in Gauteng
}

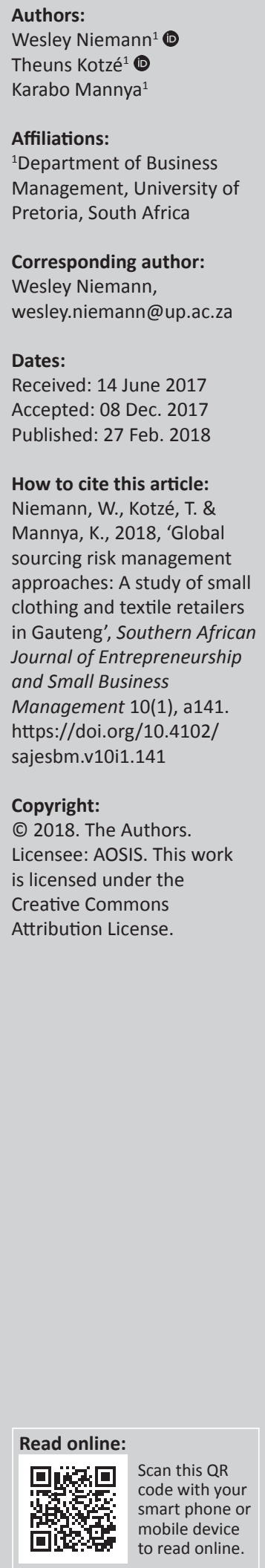

Background: Global sourcing has increased as buyers searched for new markets that offered better pricing, quality, variety and delivery lead times than their local markets. However, the increase in global sourcing has also exposed businesses to many supply risks.

Purpose: The purpose of this descriptive qualitative study was to explore the global sourcing supply risks encountered by small clothing and textile retailers in Gauteng and to determine what supply risk identification and management approaches they utilise.

Method: This study utilised semi-structured interviews conducted with 12 small clothing and textile retail owners.

Results: The study found that the three major supply risks encountered by these retailers were fluctuating exchange rates, communication barriers and costly and complicated logistics, which included high customs costs. Furthermore, although aware of the supply risks, none of the small clothing and textile retailers had formal identification and management approaches in place. Instead, risks are dealt with at the sole discretion of the owner as and when they occur. The study also found that informal identification and management approaches were being applied by some of the retailers. These included factoring exchange rate fluctuations into the profit margins and using translators to combat communication barriers.

Contribution: The study is one of the first empirical studies conducted on global supply risks and the associated identification and management approaches in the South African small business context, specifically focused on clothing and textile retailers.

Conclusion: Small clothing and textile retailers need to proactively identify and manage global sourcing risk using the identified approaches in order to reduce and mitigate potential supply disruptions.

\section{Introduction}

Although global sourcing can bring many benefits to a business, it can also expose it to several supply chain risks (Deane, Craighead \& Ragsdale 2009:861; Kumar, Himes \& Kritzer 2014:875). Disruptions in the supply chain can negatively affect the performance of a business in the short and long term, resulting in its inability to meet customer demands (Ellis, Henry \& Shockley 2010:34-35). In 2014, the outbreak of Ebola in West Africa caused major supply chain disruptions across the globe, with many countries suspending flights to and from the region. This resulted in delays in all air and sea cargo destined for Europe, Asia and the United States, mainly from Guinea (aluminium ore), Liberia (rubber), Nigeria (oil) and Sierra Leone (iron ore) (BSI 2014:2-6). Furthermore, in 2013 the 4-week strike of workers in the South African car manufacturing industry led to a supply shortage of components and a slowdown in the manufacturing of motor vehicles. This resulted in disruptions in the supply of vehicles to international markets and a daily loss of approximately R600 million for BMW, GM, Ford, Mercedes-Benz, Nissan, Toyota and Volkswagen (Williams 2013). The ripple effects of supply disruptions transcend beyond national borders, with the impact being as severe - if not more severe - for countries beyond the place where the disruptions occurred. Such supply disruptions result from the complexities associated with global sourcing (Chopra \& Sodhi 2014:74).

In South Africa, many clothing and textile retailers, both small and large, engage in global sourcing. This is because of the uncompetitive nature of the South African clothing and textile manufacturers compared to those in China and other low-cost countries, such as Bangladesh, India, Pakistan and Sri Lanka (Edwards \& Jenkins 2015:448; Yang 2014:3-5). As these clothing and textile retailers source products globally, the proactive identification and management of global sourcing risks are vital to ensure security of supply for business continuity (Faertes 2015:1400-1401). 
Muhos, Wang and Kess (2012:958) warn that small businesses can expect to be exposed to risks when sourcing globally and that they will be affected more severely because of their limited resources and lack of experience in conducting business internationally. Thun, Drüke and Hoenig (2011:5512) and Verbano and Venturini (2013:195) highlight that minimal research has been conducted globally on understanding the type of risks encountered by small businesses that engage in global sourcing and the global supply chain. In addition, only limited local studies have been undertaken on supply chain risks and global supply chains (Mndzebele 2013:16; Sayed \& Sunjka 2016:125). Furthermore, most of the literature dealing with research done in sub-Saharan Africa focuses on both small and large businesses in mining (Mndzebele 2013:1-109), manufacturing and automotive (Black 2009:483512; Maje \& Sunjka 2014:1-14; Sayed \& Sunjka 2016:122-135; Sunjka \& Emwanu 2013:1-12).

Although very few studies have been undertaken with a view to understanding the risks that small businesses encounter as a result of global sourcing and global supply chains, substantial research on this topic exists with a focus on large businesses, mainly in Europe (Christopher et al. 2011:67-81; Hoffmann, Schiele \& Krabbendam 2013:199-211; Muhos et al. 2012:968; Thun et al. 2011:5511-5525). According to these studies, various risk identification and management approaches are used by large businesses operating in various industries to address supply risks related to global sourcing and the global supply chain. Fang et al. (2013:1380) advocate the use of a contingent supplier alongside a regular supplier to mitigate risks associated with supplier delivery reliability, or alternatively the use of two regular suppliers. However, given the low volumes purchased by small businesses, in general, formalising relationships with multiple suppliers may not be viable. This could be partly because of the lack of volume leverage that makes suppliers prioritise large businesses over smaller ones (Adams, Khoja \& Kauffman 2012:20-21). Kumar et al. (2014:888) found that organisations tend to compile risk mitigation strategies based on three factors: firstly, the organisation's level of dependency on global supply; secondly, the possible impact of the potential risk; and thirdly, what the required investment is. For example, if the impact of the potential risk and the dependency on global supply are low, and the required investment of a risk mitigation strategy is high, it may be beneficial for an organisation to opt to do nothing. However, for small clothing and textile retailers, this may be a more complex decision. Because of the uncompetitive local clothing and textile manufacturing industry (Yang 2014:3-5), many of these small clothing and textile retailers are highly dependent on global supply for their products. Given this high level of dependency, the impact of disruptions in the global supply would be severe for these small clothing and textile retailers. The purpose of this descriptive qualitative study was to explore the global sourcing supply risks encountered by small clothing and textiles retailers based in Gauteng and to determine what supply risk identification and management approaches they have in place.
The following research questions guided the study:

- Why do small clothing and textile retailers in Gauteng source globally?

- What supply risks are these small clothing and textile retailers exposed to as a result of global sourcing?

- How do these small clothing and textile retailers identify possible supply risks associated with sourcing globally?

- How do these small clothing and textile retailers manage the identified supply risks?

The study contributed to both academia and practice. Firstly, it expanded on the current literature by identifying the supply risks encountered by small clothing and textile retailers in Gauteng. Secondly, the study shed light on the supply risk identification and management approaches applied by some of the small retail owners. These approaches could be beneficial for other small retail owners and managers who encounter similar supply risks, but lack knowledge on possible approaches that can be applied. Lastly, the study enhances policymakers' understanding of the supply risks encountered by small clothing and textile retailers, and thus aid them in creating solutions that enable small clothing and textile retailers to reduce or eliminate these supply risks.

\section{Literature review}

\section{Small businesses in South Africa}

So far, minimal research has been conducted on how small and medium enterprises (SMEs) assess and manage general risk (Thun et al. 2011:5512; Verbano \& Venturini 2013:195). According to Falkner and Hiebl (2015:125), this is problematic given the significant contributions that SMEs make to the economies of developing countries. The South African National Small Business Act (Act 102 of 1996) defines a small business as:

a separate and distinct business entity, including cooperative enterprises and non-governmental organisations, managed by one owner or more which, including its branches or subsidiaries, if any, is predominantly carried on in any sector or subsector of the economy. (South African Government 1996:s. 1, ss. xv, 2)

Small businesses can be classified as medium, small, very small or micro businesses, based on their total number of full-time employees, total annual turnover and total gross asset value (South African Government 1996:15). Based on the National Small Business Act (Act 102 of 1996), small clothing and textile retailers are categorised under the retail and motor trade and repair services sector. Table 1 illustrates the defining characteristics for this sector. For the purposes of this study, the term small clothing and textile retailers encompassed small, very small and micro businesses, that is, all businesses with fewer than 50 full-time employees and an annual turnover of less than R15 million (South African Government 1996:15).

According to Groepe (2015:5), small, medium and micro enterprises contribute between $52 \%$ and $57 \%$ to the South 
TABLE 1: Business classification according to the National Small Business Act (No. 102 of 1996).

\begin{tabular}{lccc}
\hline Size or class & $\begin{array}{c}\text { Total number of } \\
\text { full-time employees } \\
\text { fewer than }\end{array}$ & $\begin{array}{c}\text { Total annual } \\
\text { turnover less than } \\
\text { (R million) }\end{array}$ & $\begin{array}{c}\text { Total gross asset } \\
\text { value less than } \\
\text { (R million) }\end{array}$ \\
\hline Medium & 100 & R30 & R5 \\
Small & 50 & R15 & R2.5 \\
Very small & 10 & R5 & R0.50 \\
Micro & 5 & R0.15 & R0.10
\end{tabular}

Source: South African Governement, 1996, South African National Small Business Act No. 102 of 1996, p. 15, viewed 06 June 2016, from https://www.thedti.gov.za/sme development/docs/act.pdf

African gross domestic product. The failure rate and risks associated with running these businesses are high, regardless of whether they source globally or not (Timm 2013). Lavastre, Gunasekaran and Spalanzani (2012:834) found that French SMEs tend to attempt to reduce and address risks single-handedly, while large businesses use collaborative relationships with supply chain partners. The lack of using collaborative relationships in the supply chain to address risks could be because of SMEs having limited resources (i.e. time, money and personnel) to dedicate to risk management (Smit 2012:182). In addition, another contributing factor could be the lack of formalised relationships with suppliers because of low-volume purchases and bargaining power compared to large businesses (Lavastre et al. 2012:834). Because of the low barriers to entry and economies of scale, many of these small businesses operate in the clothing and textile industry (Kunene 2008:14).

\section{Global sourcing activities of clothing and textile retailers}

The clothing and textile industry is a typical example of a global supply chain and a major contributor to the global economy and international trade (Su \& Gargeya 2012:23-24). Turker and Altuntas (2014:838) state that globalisation has played a significant role in enabling global sourcing in many industries, including the clothing and textile industry. This industry consists of the production, marketing, distribution and selling of clothing and textiles. Figure 1 illustrates the clothing and textile supply chain. In this study, the focus was on the retail part of the supply chain, where businesses are focused on selling to end customers.

The retail portion of the clothing and textile industry is characterised by intense competition, a wide variety of products, volatile customer preferences and uncertainty in the markets (Su \& Gargeya 2012:23-24). Furthermore, it is a fast-paced environment where retailers need to be able to provide customers with items that match the latest trends in the shortest possible time (Mehrjoo \& Pasek 2016:28). These short life cycles result in markdowns or write-offs of items that do not sell fast enough (Routroy \& Shankar 2014:58). Given these and other pressures facing clothing and textile retailers, regardless of their size, it is imperative that any risks that may threaten their long-term viability and security of supply be actively minimised or eliminated (Peter 2016:324-325).

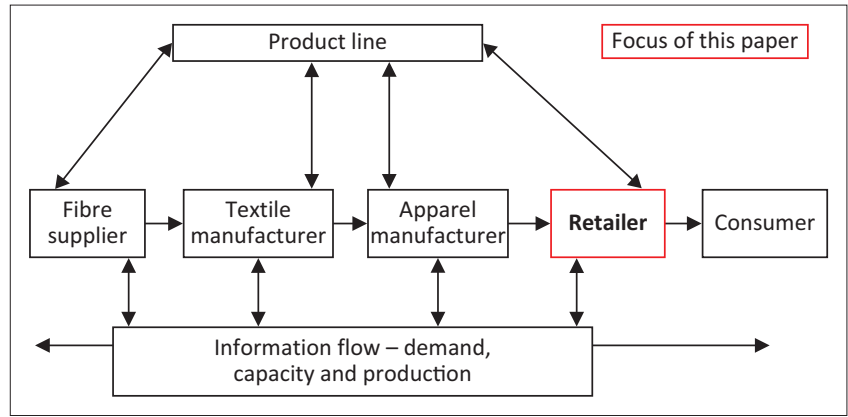

Source: Kunene, T., 2008, 'A critical analysis of entrepreneurial and business skills in SMEs in the textile and clothing industry in Johannesburg, South Africa', p. 14, viewed 15 May 2016, from http://www.repository.up.ac.za/bitstream/handle/2263/24173/Complete.pdf?sequence=10 FIGURE 1: The clothing and textile supply chain.

Berg, Berlemann and Hedrich (2013:2) and Steven, Dong and Corsi (2014:241) indicate that most clothing and textile retailers have shifted their sourcing activities to lower cost countries to enable them, among other things, to take advantage of the lower cost of labour and other resources. In addition, Jia et al. (2014:285) point out that global sourcing grants businesses, and ultimately also their customers, access to products not available in the local market.

The focus of this study was on small clothing and textile retailers in Gauteng, which is recognised as the economic hub of South Africa (Badenhorst-Weiss \& Waugh 2014:289). There has been a significant increase in the number of small clothing and textile retailers in the Gauteng area, and as a result of the uncompetitive nature of the local clothing and textile industry's manufacturers, most of them source merchandise from countries such as China, Dubai, Morocco and Thailand that offer lower cost, quicker turnaround times, more variety and better quality (Bruce, Daly \& Towers 2004:155; Yang 2014:3-4).

Holweg, Reichhart and Hong (2011:334-335) identify three factors that prompt buyers to source globally. The first of these factors is access to cheaper labour and raw materials. The second factor is access to a wider range of resources and the third factor is the opportunity to gain a presence in new markets that are supported by larger product markets and financing prospects (Manuj \& Mentzer 2008:134). All these factors were supported by the declining barriers to global sourcing as the economies of the world opened up to trade (Holweg et al. 2011:334-335).

\section{Global sourcing risks}

Kumar et al. (2014:873) note that it is difficult to predict disruptions associated with supply chain risks because of the uncertainty and variability of the risks. Routroy and Shankar (2014:53) define supply chain risk as the degree to which supply chain outcomes are unpredictable or vulnerable to disruptions. Furthermore, Ho et al. (2015) define it as:

the likelihood and impact of unexpected macro and/or micro level events or conditions that adversely influence any part of a supply chain resulting in operational, tactical, or strategic level failures or irregularities. (p. 5035) 


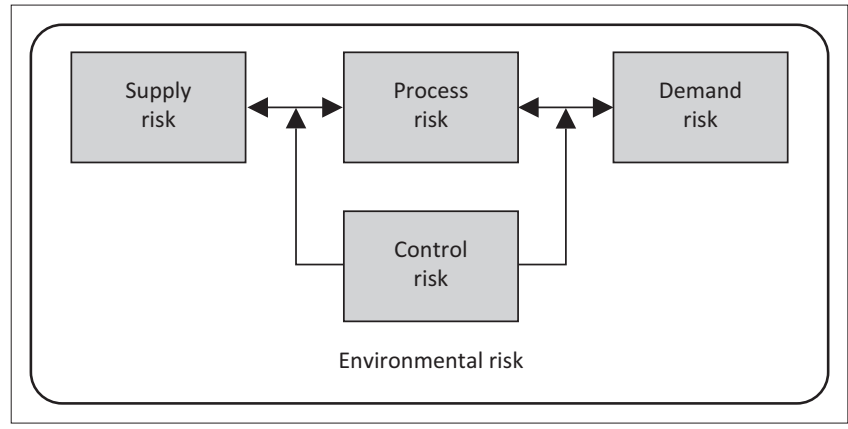

Source: Christopher, M., 2011, Logistics and supply chain management, 4th edn., p. 195, Pearson Education, Great Britain

FIGURE 2: Sources of risk in the supply chain.

According to Christopher et al. (2011:68) and Routroy and Shankar (2014:53), risk categorisation is based on the source of the risk, with these sources being supply, demand, process, control and environmental risk. Supply and demand risks are both internal to the focal firm (Srinivasan, Mukherjee \& Gaur 2011:262); process and control are external to the focal firm but internal to the supply chain; and environmental risks are external to both the focal firm and the supply chain (Christopher et al. 2011:68). Figure 2 depicts the relationships between the various sources of risk in the supply chain.

Global supply chains have opened up opportunities for small and large businesses to source globally and are concerned with movement of goods from suppliers in one country to buyers who are in another country. The intention is for the buyer to ultimately sell these goods to customers in their local market (Borges 2015:12). Deane et al. (2009:863) point out that global supply chains are complex and everevolving because of the many uncertainties they face. As a result of these uncertainties, global supply chains are exposed to various kinds of risks (Brammer, Hoejmose \& Millington 2011:8) and can become costly if not well coordinated (Christopher 2011:171).

Holweg et al. (2011:334) define global sourcing as the sourcing of finished or intermediate products from other countries, with the intention to sell them to customers in the buyer's local market. For this qualitative study, global sourcing risks were categorised as supply, demand, process, control and environmental risks (Christopher et al. 2011:69), with the focus on supply risks associated with global sourcing.

Demand risk, which is associated with the movement of items from the focal firm to the customer, can arise as a result of inbound disruptions, such as seasonality, short product life cycles, volatile customer demands and the adoption of new products (Srinivasan et al. 2011:264). Process risks relate to the internal ability of the firm to make goods or provide services (Pfohl, Köhler \& Thomas 2010:34). This risk is about the resilience of the manufacturing and production processes. Control risk relates to how an organisation's own internal control systems are likely to cause disturbances and distortions. For instance, safety stock policies can obscure real demand (Christopher 2011:194). External factors usually
TABLE 2: Identified supply risks associated with global sourcing activities.

\begin{tabular}{ll}
\hline Author & Identified supply risks \\
\hline Ho et al. (2015:5045) & $\begin{array}{l}\text { Uncertainty about the supplier's capacity, } \\
\text { late delivery, poor quality and poor } \\
\text { supplier service }\end{array}$ \\
$\begin{array}{l}\text { Holweg et al. (2011:334-335); } \\
\text { Jiang and Tian (2009:19) }\end{array}$ & $\begin{array}{l}\text { Supplier reliability, complicated and costly } \\
\text { logistics, volatile economic and political } \\
\text { environments, and communication and } \\
\text { cultural barriers }\end{array}$ \\
Manuj (2013:90) & $\begin{array}{l}\text { Political stability, cost of quality, currency } \\
\text { fluctuations, increased lead times, rising } \\
\text { fuel and transportation costs }\end{array}$ \\
Nunes (2016:147) & $\begin{array}{l}\text { A decrease in the business's agility and } \\
\text { flexibility; an increase in distance, cost and } \\
\text { the number of intermediaries in the } \\
\text { supply chain; the failure of logistics } \\
\text { support; dealing with cultural differences, } \\
\text { regulations and uncertainty in a country }\end{array}$ \\
Ray and Jenamani (2016:239) & $\begin{array}{l}\text { The multiple possible reasons for failure in } \\
\text { supply include insufficient supply of items } \\
\text { or late to no delivery of the required items } \\
\text { because of disruptions in the production } \\
\text { process (i.e. machine breakdown), labour } \\
\text { strikes, financial defaults and natural } \\
\text { disasters }\end{array}$ \\
\hline
\end{tabular}

drive environmental risks such as weather, market forces and political issues, which are all able to affect the supply chain (Lockamy 2014:756). For this study, the focus was extended to understanding supply risks.

\section{Supply risks}

Pfohl et al. (2010:36) define supply risks as those that result in an interruption of the flow of goods from the supplier to the customer while Palaniappan (2014:22) defines supply risks as a business suppliers not being able to deliver required supply completely or on time. This impacts the ability of the business to ultimately deliver to the customers. Supply risks are associated with inbound supply and are concerned with the movement of material from the supplier to the purchasing firm and arise because global sourcing lengthens the supply chain (CIPS 2013:1). Thus, for businesses involved in global sourcing, supply risks increase even more as they have to deal with risks beyond the borders of the country in which they conduct their business (Chopra \& Sodhi 2014:74). Table 2 summarises and indicates some of the supply risks that businesses can encounter because of globalisation.

In this study, these risks will be classified as follows: supplier reliability, complicated and costly logistics, fluctuating exchange rate, communication and cultural barriers and political and environmental volatility (Holweg et al. 2011:334-335; Jiang \& Tian 2009:19).

Supplier reliability: Supplier failure as a result of disruptive events internal or external to the supplier can cause enormous loss and delays to buyers' ability to deliver to their customers (Ray \& Jenamani 2016:238). Issues such as lack of capacity, poor quality and late deliveries can all compromise the supplier's reliability (Holweg et al. 2011:5045).

Complicated and costly logistics: Complicated and costly logistics result from increased delivery lead times, high customs costs and complicated customs requirements, 
increased fuel prices and the consequent increases in transport costs (Jiang \& Tian 2009:18), which all increase the likelihood of supply risks for businesses. Jain, Girotra and Netessine (2014:1202) mention that one of the disadvantages of global sourcing is the increased lead times that arise as a result of cross-border transit and customs clearance times. Adding to this, Berg et al. (2015:21) highlight the fact that all the administration around compliance with customs regulations could result in unexpected delays in buyers' attempts to have their products cleared and delivered to customers on time. Halldórsson and Kovács (2010:8-9) note that travelling and transport costs are highly likely to be escalated whenever the fuel price increases. All these complicated and costly logistical issues could result in the late arrival of the supplies required.

Fluctuating foreign currency: Borges (2015:17) indicates that exchange rate fluctuations can have either minor or major impacts on businesses that source merchandise globally. Fluctuations in exchange rates result in items being more expensive for the buyer (Gheibi, Kazaz \& Webster 2016:2), as they usually diminish the purchasing power of the business. In addition, exchange rate fluctuations not only impact on the purchasing price but also impact on the profit margins of the business (Young 2016:4).

Communication and cultural barriers: Towers and Song (2010:529) found that communication and cultural barriers remain as major challenges, especially for businesses that have minimal sourcing experience in that sourcing country. Borges (2015:17) states that culture refers to conduct and beliefs that are acceptable in a particular global region. Communication and cultural barriers encompass the language used, which Oke, Maltz and Christiansen (2009:158) found to provide a good basis for facilitating transactions and lowering transaction costs. Jiang and Tian (2009:19) highlight that the risk associated with communication misunderstandings cannot be underplayed. This is because clear communication between the buyer and supplier provides the buyer with better negotiating grounds.

Political volatility and environmental conditions: Political volatility and environmental conditions are regarded as external risks that do not originate from the supply chain, but can have major impacts on them. Colicchia and Strozzi (2012:409) indicate that political and environmental risks are part of external supply chain risks, which are not within the control of the focal firm. However, these external risks can have major impacts on the focal firm. These external risks may arise from natural disasters, epidemics, political instability and wars. Businesses that source merchandise globally are exposed to supply risks when incidents of political unrest and adverse environmental conditions occur in the countries from which they source products (Jain et al. 2014:1205).

\section{Global sourcing risk identification approaches}

Kırılmaz and Erol (2017:56) highlight that risk identification is the most important step in the supply chain risk management process (SCRMP) as it triggers any further need for a business to do risk assessment or management. The SCRMP involves the identification, assessment and management of risks (Kırilmaz \& Erol 2017:56). For this study, risk identification and management were the key focus. Risk identification involves identifying potential internal and external risks that can impact the business (Hoffmann et al. 2013:202; Smit 2012:62; Wieland \& Wallenburg 2012:656). Many risk identification approaches exist in the literature such as the fault-tree analysis, event tree analysis, risk checklists and catalogues, strengths, weaknesses, opportunities and threats (SWOT) analysis, risk breakdown structures, internal business brainstorming session of risks and review of risk literature among others (Kırılmaz \& Erol 2017:56; Sherwin, Medal \& Lapp 2016:155; Tummala \& Schoenherr 2011:475-476; Vilko 2012:45). However, in this study the approaches that could potentially be applied by the small clothing and textile retailers are explored. These approaches could be beneficial to small businesses given that they are simple to use and require minimal resources (Barroso, Machado \& Machado 2011:169; Murray-Webster 2010:88):

- Supply chain mapping: Entails the mapping of the entire supply chain from the supplier to the customer, thereafter identifying along that value chain what possible risks could be encountered.

- PESTEL analysis: A simple framework that is commonly utilised in risk identification. Risks are identified along political, economic, sociological, technological, environmental and legal dimensions (Peace 2013:5). It may be helpful for the small clothing and textile retailers as it is a simple framework. However, Hopkin (2017:138139) indicates that gaining access to external data of high quality along these dimensions may prove to be time consuming and expensive.

- Supplier pre-buying review: Gathering information on potential and current suppliers from publicly available information (Falkner \& Hiebl 2015:133; Smit 2012:62) could be done by using online portals and e-marketplaces as a source of information on potential suppliers. In addition, buyers can visit a supplier's premises to get a sense of the supplier's product offering, quality control systems and production capacity (Palaniappan 2014:22).

\section{Global sourcing risk management approaches}

Olson and $\mathrm{Wu}$ (2010:697) indicate that because businesses that are engaged in global sourcing cannot avoid supply risks, it is imperative that managers establish ways of managing these risks. Risk is part of purchasing, especially because the purchasing business has very little to no control over the suppliers. There is thus an incentive for businesses to find the correct mix of risk reduction practices, given their available resources (Ellegaard 2008:425-432). According to Chopra and Sodhi (2014:74), managers who engage in the 
proactive management of supply risk add value to their businesses through reduced risk and higher cost efficiency. Because very few businesses, regardless of size, have formal processes in place for managing supply risk, those that do make provision for such processes create a competitive advantage for themselves (Dittmann 2014:5).

Several risk management approaches that could be applicable to small businesses for addressing risks that arise because of global sourcing are discussed below. The approaches require a small cost element such as insurance, hedging and dual transportation, while local sourcing, probability reduction and increasing sourcing partners should be implementable with minimal to no additional cost. The low-cost element is essential for small businesses as they have limited resources available (Smit 2012:182).

- Insurance: Usually, insurance companies have formalised processes for assessing and managing risks, which makes the use of insurance beneficial to the businesses that use them (Kunreuther \& Pauly 2014:2). Insurance can be used to cover for supply risks such as supplier defaults or delays (Sodhi, Son \& Tang 2012:2). Despite the viability of insurance as a risk management approach, Abe and Ye (2013:571) found that SMEs were highly underinsured. This could be because of the cost associated with insurance (Olson \& Wu 2010:698). In addition, Dittmann (2014:7) found that few supply chain professionals across retail, manufacturing and services businesses of varying sizes used insurance as a measure to mitigate risk.

- Increasing sourcing partners: Jain et al. (2014:1206) recommend that to ensure delivery reliability, a business may need to increase its supplier base and source from multiple partners. As highlighted by Ray and Jenamani (2016:238), multi-sourcing is considered a common practice to hedge against supply risks, and although it does not eliminate the occurrence of such risks, it does reduce the probability or the impact of disruption. Berg et al. (2015:5) point out that sourcing activities can be allocated across multiple countries to minimise the impact of supply risks that may arise in one country.

- Hedging: Jain (2013:26) indicates that hedging can be a means of minimising or eliminating foreign currency fluctuations for businesses at a cost. This could be particularly helpful for a small business that has access to limited cash flows and whose purchases are heavily reliant on foreign exchange. Young (2016:4-5) indicates that there are pros and cons to hedging and thus a thorough assessment of the market before selecting a hedging option or forward is essential.

- Risk probability reduction: This entails a business complete avoidance or elimination of the occurrence of a supply risk. This is achieved by choosing to avoid purchasing from certain suppliers or countries or certain products (Ellegaard 2008:432).

- Dual transportation: This entails the splitting of a single batch order into two and using different transport providers (Christopher \& Holweg 2011:71). This will ensure that should one transport provider delay or lose the merchandise, the other batch will still be delivered to the buyer (Micheli, Mogre \& Perego 2014:123).

- Local sourcing: Several arguments for local sourcing are highlighted by CIPS (2013:1-2). These included the increasing transport costs of moving goods, increasing supply chain risks such as extended lead times and exchange rate risks, and the heightened focus on sustainability in terms of businesses needing to reduce their carbon footprint (CIPS 2013:1-2). This aligns with Hendry, Sayed and Zorini (2015:3-4) and Shen (2014:6241) who also found that local sourcing results in reduced distances, the reduction in delivery lead times, product leftovers and carbon emissions.

- Supplier relationship development and management: Ho et al. (2015:5049) and Ellis et al. (2010:38) found that building strategic relationships with certain suppliers was beneficial but required time commitments from the buyer. In addition, Faes and Matthyssens (2009:246) highlight that loyalty sourcing, which is repeat buying from a single supplier with or without the use of contracts, enhances buyer and supplier relationships. This provides better grounds for negotiation for the buyer.

\section{Methodology Research design}

This study followed a descriptive qualitative research design. Plano Clark and Creswell (2015:289) state that the purpose of a descriptive qualitative research design is to explore a phenomenon by exploring different perspectives on a topic through the identification of underlying themes that emerge from discussions with participants. A descriptive qualitative research design was deemed appropriate as the aim of this study was to explore the perceptions of small clothing and textile retailers in Gauteng regarding the global sourcing supply risks they encounter and the risk identification and management approaches applied to address these supply risks.

\section{Sampling}

The unit of analysis consisted of 12 small clothing and textile retail owners based in Gauteng who are engaged in global sourcing. A total of 12 semi-structured interviews were conducted. According to Guest, Bunce and Johnson (2006:76), for a homogenous group, saturation is likely to be achieved at around 12 interviews. Further interviews are likely to provide minimal to no new insights. In this study, saturation occurred after the 11th interview. One additional interview was conducted whereafter data collection was terminated.

Purposive sampling was used for this study as it allowed for the identification and selection of information-rich individuals who could provide the required information (Palinkas et al. 2015:533). The small clothing and textile retail owners in the sample were all solely responsible for all sourcing and risk-related decisions, except two who coowned the business each with one other person. In addition, 
TABLE 3: Details of the small retail owners who participated in the study.

\begin{tabular}{|c|c|c|c|c|}
\hline Pseudonym & Sourcing location & $\begin{array}{c}\begin{array}{c}\text { Percentage of merchandise } \\
\text { sourced globally }\end{array} \\
\end{array}$ & $\begin{array}{l}\text { Gender of the small } \\
\text { retail owners }\end{array}$ & $\begin{array}{c}\text { Duration of interview } \\
\text { (minutes) }\end{array}$ \\
\hline $\mathrm{B} 1$ & $\begin{array}{l}\text { China, Democratic Republic of } \\
\text { Congo and Thailand }\end{array}$ & 35 & Male & 48 \\
\hline B3 & Ghana & 100 & Female & 33 \\
\hline B4 & Turkey and the United Kingdom & 100 & Male & 32 \\
\hline B5 & $\begin{array}{l}\text { Brazil, Canada, the United Kingdom } \\
\text { and the United States }\end{array}$ & 60 & Female & 48 \\
\hline B6 & China and Turkey & 100 & Female & 26 \\
\hline B7 & Ghana & 100 & Female & 37 \\
\hline B8 & Turkey & 100 & Female & 23 \\
\hline B9 & Turkey & 100 & Female & 54 \\
\hline B10 & Ghana, Nigeria and Mozambique & 100 & Female & 31 \\
\hline B11 & China, Italy and Turkey & 100 & Female & 20 \\
\hline B12 & China, Ghana, Kenya and Nigeria & 70 & Female & 28 \\
\hline
\end{tabular}

two purposive sampling strategies were used in this study, homogenous and snowballing. Homogenous sampling allowed for the selection of individuals based on specific characteristics (Plano Clark \& Creswell 2015:334), which allowed for reduced variations and a more focused investigation. All the selected small clothing and textile retailers were based in Gauteng and were engaged in the global sourcing of clothing or textiles for resale on the local market. The second purposive sampling strategy that was applied was snowballing. This strategy was used to identify additional participants based on the recommendations made by the initial group of participants (Plano Clark \& Creswell 2015:334; Polit \& Beck 2012:517). Six of the 12 individuals who were interviewed were recommended by other participants. Details of the 12 individuals who were interviewed are presented in Table 3.

\section{Data collection}

The primary source of data was semi-structured interviews. Two of the interviews were conducted face to face, while the rest were telephonic interviews because of logistical constraints. The interviews were conducted between August 2016 and April 2017. According to Saunders, Lewis and Thornhill (2009:320), semi-structured interviews are most appropriate for prompting participants to provide detailed information. Semi-structured interviews were deemed appropriate as the aim of this study was to prompt small clothing and textile retailers to provide insights regarding the global sourcing supply risks they encounter. Additionally, the aim was to also understand what risk identification and management approaches they applied to address these supply risks. The researcher made use of the discussion guide from the study undertaken by Christopher et al. (2011:67-81). The discussion guide was pretested with a supply chain management academic and a methodology expert and with one of the identified small clothing and textile retailers. Some of the questions were amended following the pretest to ensure that all the questions included in the interview would contribute towards providing the information needed to answer the main research questions. An introductory email was sent to the participants to inform them of the context of the study and to obtain permission for their inclusion in the study. The interviews were audiorecorded and the duration of the interviews varied from 20 to $54 \mathrm{~min}$, averaging $33 \mathrm{~min}$. The researcher transcribed all audio recordings and replayed them while reading the transcripts to ensure the accuracy of the transcripts. Corrections were made where needed.

\section{Data analysis}

A thematic analysis allowed the researcher to identify, organise and highlight patterns concerning the research questions (Braun \& Clarke 2012:57). A combination of both deductive and inductive approaches to thematic analysis was applied. The deductive approach allowed use of some of the already existing themes in the literature on supply risks, risk identification and management approaches. Inductive approach ensured that certain themes were derived purely from the data, and supporting literature was then identified. The six-phased thematic analysis process recommended by Braun and Clarke (2012:60-69) was followed. Familiarisation with the data was done by repeatedly listening to the audio recordings and making notes on the transcripts. This was done using the Microsoft Word comments tool. Then initial codes were generated by extracting data from the transcripts and notes made on them. The formulation of themes was done by identifying patterns across all the derived codes and grouping similar codes into sub-themes and then into main themes. Revision of all main themes was done to ensure no overlapping across the themes occurred. Each theme was then given a clear definition. The write-up of the findings was guided by the main themes and their link to the relevant research questions.

\section{Trustworthiness}

To ensure trustworthy findings, qualitative research needs to reflect transferability, confirmability, credibility and dependability (Shenton 2004:63). To ensure transferability, detailed descriptions of the research context, the participants and the research topic were provided (Polit \& Beck 2012:526). To ensure confirmability and credibility, a triangulation strategy was used. This entailed having a wide range of informants, which allowed for the corroboration and 
verification of individuals' opinions and experiences against others. This ultimately made it possible to provide 'a rich picture of the attitudes, needs or behaviour of those under scrutiny' (Shenton 2004:66). Peer debriefing ensured that trustworthiness issues could be identified and corrected (Polit \& Beck 2012:594).

\section{Ethical considerations}

Ethical clearance for this study was obtained from a research ethics committee at a South African university prior to conducting fieldwork. To comply with the ethical principle of informed consent and voluntary participation, all the participants were required to read and sign the informed consent form. To ensure anonymity and confidentiality, the names of the participants and businesses were replaced with pseudonyms, which are listed in Table 3. Finally, the study adhered to the protection from harm principle as it did not focus on any psychologically sensitive issues.

\section{Findings}

The research identified key themes that aid in answering the initial research questions posed. Firstly, it identified the factors that influence why small clothing and textile retailers are engaged in global sourcing activities. Secondly, it identified the supply risks encountered by these small clothing and textile retailers as a result of their global sourcing activities. Thirdly, it indicated the risk identification approaches used by these small clothing and textile retailers. Lastly, it identified the risk management approaches, which many of the small clothing and textile retailers indicate are informal and are used to manage some of the identified supply risks. The findings of the analysis are summarised in Table 4.
The findings are discussed in the next section.

\section{Reasons for global sourcing}

\section{Access to lower cost goods and better quality}

Several factors influence why businesses source globally regardless of size. For the small clothing and textile retailers in this study, access to lower cost goods of better quality were major influencing factors for their sourcing globally from countries like China and Turkey. This aligns with Berg et al. (2013:2) who found that lower cost countries that offer superior quality goods are attractive sourcing locations for many businesses regardless of size. In addition, Yang (2014:3-5) highlights that the uncompetitive clothing and textile manufacturing industry in South Africa struggles to compete with a country like China in terms of lower pricing and quality:

'... initially China was primarily on price, because you know that their stuff is quite cheaper compared to other areas. And then with Turkey, I think what influenced me was the quality on the apparel.' [B6, Female, Owner]

'I think the quality of the clothing, the type of material. There was a time when we tried to make clothing locally, and use local seamstress, and things like that to get them to make clothes for us and it just isn't the same.' [B2, Female, Co-owner]

\section{Limited or lack of local supply and access to more variety}

The lack of local suppliers and the limited local supply in terms of variety were also found to be push factors for the small clothing and textile retailers to source globally. This aligns with Jia et al. (2014:285) and Mehrjoo and Pasek (2016:28), who highlight that global sourcing grants businesses access to more variety of the latest trends and products not available in the local markets:

TABLE 4: Summary of findings.

\begin{tabular}{|c|c|c|c|c|c|c|c|c|c|c|c|c|}
\hline $\begin{array}{l}\text { Research questions and themes derived from participants' } \\
\text { responses }\end{array}$ & B1 & B2 & B3 & B4 & B5 & B6 & B7 & B8 & B9 & B10 & B11 & B12 \\
\hline \multicolumn{13}{|c|}{ Why do small clothing and textile retailers in Gauteng source globally? } \\
\hline Lower cost & $\mathrm{x}$ & $\mathrm{x}$ & - & $\mathrm{x}$ & - & $\mathrm{x}$ & - & - & $x$ & $x$ & - & $x$ \\
\hline More variety & $\mathrm{x}$ & - & - & - & - & - & - & $x$ & - & $\mathrm{x}$ & - & $x$ \\
\hline No local supplier & - & - & $\mathrm{x}$ & - & - & - & $\mathrm{x}$ & - & - & - & - & $x$ \\
\hline Ease of access to market (i.e. familiarity or have local contacts) & $\mathrm{x}$ & - & $x$ & - & $x$ & - & $x$ & - & $x$ & $x$ & - & $x$ \\
\hline Fluctuating exchange rate & $\mathrm{x}$ & $x$ & $x$ & $\mathrm{x}$ & - & $\mathrm{x}$ & $x$ & $x$ & $x$ & - & - & - \\
\hline Communication and cultural barriers & $x$ & - & - & $\mathrm{x}$ & $x$ & $x$ & $x$ & $x$ & - & $x$ & $x$ & $x$ \\
\hline Costly and complicated logistics & $x$ & $\mathrm{x}$ & $x$ & $x$ & - & $x$ & - & $x$ & $x$ & $x$ & $x$ & $x$ \\
\hline Supplier reliability & $x$ & $x$ & $x$ & - & - & $\mathrm{x}$ & - & - & - & $x$ & $x$ & $x$ \\
\hline Political volatility and adverse environmental conditions & $\mathrm{x}$ & $\mathrm{x}$ & - & - & - & - & $\mathrm{x}$ & - & $x$ & $\mathrm{x}$ & $\mathrm{x}$ & \\
\hline \multicolumn{13}{|c|}{ How do these small clothing and textile retailers identify potential supply risks associated with sourcing globally? } \\
\hline Landscape analysis & $\mathrm{x}$ & - & - & $\mathrm{x}$ & $x$ & - & - & - & - & $x$ & - & $x$ \\
\hline Supplier pre-buying review & - & $x$ & - & $\mathrm{x}$ & $x$ & $\mathrm{x}$ & - & $x$ & - & - & - & $x$ \\
\hline Exchange rate monitoring & $x$ & - & $x$ & - & - & - & - & - & - & $x$ & - & $x$ \\
\hline \multicolumn{13}{|c|}{ How do these small clothing and textile retailers manage the identified supply risks? } \\
\hline Informal supplier relationship management & - & - & - & - & - & - & - & - & $x$ & - & - & - \\
\hline Exchange rate fluctuation buffers & $\mathrm{x}$ & - & - & - & $\mathrm{x}$ & - & - & - & - & - & - & - \\
\hline Dual transportation & - & - & - & $x$ & - & - & - & - & - & - & - & - \\
\hline Communication management & - & - & - & - & $x$ & - & - & - & $x$ & - & - & - \\
\hline Local sourcing & - & - & - & - & - & - & - & - & - & - & - & $x$ \\
\hline
\end{tabular}


'But the whole point is the fact that it comes from West Africa, because there is no one who manufactures it here, it is not a South African thing.' [B3, Female, Owner]

'You have a wide variety of things to choose from ....' [B8, Female, Owner]

\section{Ease of access to the market and familiarity with the sourcing market}

A new influencing factor found in this study was that several small clothing and textile retailers also indicated that their familiarity with the sourcing market whether personally or having friends and family in those markets also influenced their choice of sourcing countries. Familiarity with the sourcing market was also supported with the ease of access to the market. Most of the small clothing and textile retailers indicated that the areas they source from were arranged as 'market-like setups' geared for trade. This supports Baldwin (2012:34) who indicates that, 'since firms source intermediate inputs from other firms, the presence of many firms in a given location tends to make that location attractive'.

\footnotetext{
'...my focus is not only on like Ghana per se, but I do want to bring out to other parts of Africa. But I think for now, it's just that I find it easier because I am from there and I know where to get the stuff and how much it costs, and how it works and stuff.' [B7, Female, Owner]

'Well, the thing is Nigeria was an easy access for me because I already have people that I know there.' [B10, Female, Owner]

'I think you know there's certain places that are destinations of trade so like by the time we step into Guangzhou there is literally a building that's like 15 stories high and it is geared to trade with people from other markets on particular things.' [B12, Female, Co-owner]
}

\section{Supply risks encountered by the small clothing and textile retailers}

This study identified several supply risks that small retail owners encountered because of global sourcing. These risks were categorised as complicated and costly logistics, fluctuating exchange rates, communication and cultural barriers, supplier reliability and volatile political environments.

\section{Complicated and costly logistics}

These are all the costs associated with the business owner travelling to and from the supplier, having items cleared by customs or having the items couriered or delivered to them. All the business owners indicated that customs remained a major challenge, with many of their items being either lost or damaged. In addition, they would also experience delays in the clearing of their items. This aligns with Jain et al. (2014:1202) and Berg et al. (2015:21) who mention that global sourcing exposes businesses to increased lead times because of cross-border administration and customs clearance and higher transport costs as distance and fuel prices increase:

'Customs mm, yeah, they are always a problem. They are always a problem, there is a lot of corruption in customs. Essentially, I lose a lot of stuff to customs.' [B1, Male, Owner]

\begin{abstract}
'... the issue that we face as an African continent is that our imports and exports prices are very high. The cost that you will be charged as a small start-up business doesn't make sense in terms of your bottom line.' [B3, Female, Owner]
\end{abstract}

\section{Fluctuating exchange rates}

Most of the small clothing and textile retailers indicated that they paid for their purchases in US dollars. Thus, the constant fluctuations of the rand against the dollar tended to decrease their purchasing power. This aligns with Gheibi et al. (2016:2) and Young (2016:4) who highlight that exchange rate fluctuations impact not only on the businesses' purchasing power but also on profit margins. As found in this study, some of the small clothing and textile retailers indicated that exchange rate fluctuations meant that they have had to take profit margin cuts as they could not increase the selling price for their customers as often as the fluctuating exchange rate.

'Exchange rate fluctuations definitely, it is quite difficult. We started the business in 2014, 2013 actually - I can't even remember now. But the dollar was R9....' [B2, Female, Co-owner]

'Clients don't care about that, if you gave them a price a month ago, the fact that the rand has gotten low doesn't justify it in terms of charging them more today.' [B4, Male, Owner]

\section{Communication and cultural barriers}

Inability to clearly communicate with suppliers because of language meant that some of the small retail owners could not negotiate for better prices or ended up with delayed output. It also limited their ability to freely travel in some of these countries that they sourced from, unless they were originally from there or had assistance from a local. In addition, the cultural differences were also seen as a supply risk, as sometimes the health of the small clothing and textile retail owner would be compromised because of not being acquainted with the diet there. This would sometimes result in the small clothing and textile retail owner not being able to secure all the supplies they require on time as a result of health issues. This aligns with Oke et al. (2009:158) and Towers and Song (2010:529) who indicate that language barriers and cultural differences remain huge challenges in global sourcing and can also deter effective negotiation for the buyer (Jiang \& Tian 2009:19):

'Language barriers, my God!!! It is a big thing (laughs). Language barrier is a big thing. So, you are not able to negotiate because of language barriers, you are unable to negotiate proper prices.' [B10, Female, Owner]

'No, they are always a challenge, and that is why in some countries you have got to have an agent if you want to save time because language barrier and cultural barriers are different so they will always be a challenge [risk].' [B11, Female, Owner]

'Being in this area where it is not the same diet and so you get a running tummy over the next three days, so it is kind of difficult ....' [B1, Male, Owner]

\section{Other supply risks encountered by small clothing and textile retailers}

Other supply risks were mentioned by some of the small retail owners. However, they were not mentioned by as many small 
clothing and textile retailers as the supply risks identified above. These included supplier reliability, political volatility and adverse environmental conditions. Supplier reliability included issues such as poor quality from suppliers, which was usually an issue if the small retail owner presented the supplier with a specific design. In addition, stock unavailability meant that sometimes when certain items had been popular with their customers, these small clothing and textile retailers were unable to purchase more as suppliers had run out with no indication of when the item would be available. Failure by the supplier to meet deadlines in terms of production output and increased delivery lead times also had a knock-on effect on supplier reliability. All the issues raised with regard to supplier reliability align with Ho et al. (2015:5045) and Ray and Jenamani (2016:239) who also identified poor quality, insufficient supply and late or no delivery from supplier:

'... they don't check all the merchandise that they send, so sometimes you find that they send you something that has a fault.' [B6, Female, Owner]

'... they are not reliable ... I mean it once happened where I started negotiating with a supplier while I was here [South Africa] and I gave her deadlines of when I would be, when the dates I will be in Nigeria, and therefore my stock, she needed to be finished making my bags by the time I get there. And I mean she wasn't finished, she wasn't finished!' [B10, Female, Owner]

'....and if something was a hit you can't repeat a particular style because that space isn't that formalized you know, so you are literally going and sourcing from the women in the markets.' [B12, Female, Co-owner]

Political volatility and adverse environmental conditions were not mentioned as frequently by the participants. Those who did mention them raised issues such as the presence of specific political instabilities within the country [recent xenophobic attacks in South Africa], and even in the sourcing countries, as being hindrances for small clothing and textile retailers to continue with planned buying trips. Environmental conditions highlighted included adverse weather conditions in sourcing countries that the small retail owners were not particularly acclimatised to. As highlighted by Colicchia and Strozzi (2012:409), political and environmental conditions are external to a supply chain and out of the control of the focal firm:

'...where [China] the weather is extremely hard.' [B1, Male, Owner]

'And ya personally the only other place that we go and that we are considering to go to is Istanbul but now because of all the fighting we can't go there.' [B2, Female, Co-owner]

'I mean now there is this whole xenophobia issue that we are having. ... Trust me, I will not travel at this time when we are experiencing xenophobia in South Africa; I will not travel to those countries around the same time ....' [B10, Female, Owner]

\section{Informal supply risk identification approaches used by the small clothing and textile retailers}

Ates et al. (2013:35-36) highlight that SMEs tend to generally not have formalised decision-making processes in place. This aligns with findings from this study where although aware of the possible supply risks, none of the small clothing and textile retailers indicated having formal risk identification approaches in place. Instead, several informal risk identification approaches were applied, all at the discretion of the small clothing and textile retail owner.

\section{Landscape analysis}

Some of the small retail owners indicated that they assess how favourable the economic, environmental and political landscapes are for a buying trip. This entails assessing the landscape of both the small retail owners' country and the sourcing countries. The landscape analysis usually entails online research of the political, economic and environmental aspects. The outcome from this online research would determine whether a buying trip should proceed as planned or be put on hold. This aligns with Hopkin (2017:138-139) and Peace (2013:5) who advocate for the use of PESTEL analysis to identify things such as political stability, exchange rate fluctuations and understanding cultural norms:

'I go online and see what the current affairs are that are happening there and also to check tabs on the economy to before I travel.' [B1, Male, Owner]

'So most importantly is I will check how the weather is there [sourcing country]. Sometimes depending on what season, it is it could be a very raining season and then my trip is fruitless in terms of me being there you know.' [B10, Female, Owner]

\section{Product quality checks}

This entails small retail owners identifying any quality or design problems. The aims of the checks for the small clothing and textile retail owner is to ensure that the output of the products complies with and meets the order specifications in terms of quality and design. This is done before the supplier packages the items. None of the small clothing and textile retailers had quality management systems in place. Instead, quality is based on the discretion of the owner. Although this is done informally without the use of actual checklists or catalogues, it aligns with Tummala and Schoenherr (2011:475-476) who advocate for the use of a risk checklist and catalogue to identify potential risks:

'So instead of dealing with the backlog, for me it is much simpler if I buy a ticket and then make sure that the things that I have bought I am satisfied with it.' [B6, Female, Owner]

'You have to check before they [suppliers] wrap their merchandise to be shipped.' [B11, Female, Owner]

\section{Supplier pre-buying review}

Supplier pre-buying reviews are usually done by the small clothing and textile retail owner to check suppliers' business profiles using online searches, and to also review any performance reviews that could have been posted by other buyers on the suppliers' web page. Information is sourced from business websites and social media platforms such as Facebook and LinkedIn. This is in line with Falkner and Hiebl (2015:133) and Smit (2012:62) who advocate for gathering information on potential and current suppliers from publicly available information: 
'Oh ok, on the platform we also check the uhm reviews, so we check reviews and feedback from other people who have bought from them [suppliers].' [B2, Female, Co-owner]

'You can now even use LinkedIn to find out more about your suppliers. You know in fact social media has made it all so simple and you don't have to travel and can do everything online.' [B5, Female, Owner]

\section{Exchange rate monitoring}

Exchange rate monitoring involves conducting regular checks of the exchange rate to assess the performance of the rand against the US dollar. Most of the participants indicated that this was important as most of their purchases were paid for using the US dollar. Use is made of online news sites and forex companies such as Bidvest to obtain forex information. This aligns with Hopkin (2017:138-139) and Peace (2013:5) who advocate for the use of PESTEL analysis to identify things such as exchange rate patterns:

'Ya the dollar exchange rate I watch every day (emphasis again every day). I listen for it very closely because I know that my business is very dependent on it.' [B2, Female, Co-owner]

'... if I had goods overseas and I had to send them here, I would say they must hold so that you can assess the rand volatility, and until it stabilises a little bit then you can send them if you want to save costs.' [B11, Female, Owner]

\section{Informal supply risk management approaches used by small clothing and textile retailers}

Christopher et al. (2011:67-81) found that large UK-based businesses followed no formal risk management approaches, but relied on the sole experience and discretion of the supply chain manager. This aligns with the findings of this study, where even small clothing and textile retailers indicated not having any formalised approaches, but made use of informal approaches to managing possible supply risks. These were applied at the sole discretion of the owners. These included establishing and building informal supplier relationship building, exchange rate buffers, use of dual transportation and communication management to facilitate trade with suppliers.

\section{Informal supplier relationship building and management}

Although Ho et al. (2015:5049) and Ellis et al. (2010:38) found that building strategic relationships with suppliers proved beneficial for buyers, this study found that very few small clothing and textile retail owners engaged in strategic supplier relationship building and management. For those small clothing and textile retailers who did engage in relationship building and management, it was done very informally without the use of formal service-level agreements nor contracts. This was done over time by learning the language, cultural practices and business practices of the sourcing countries to engage better with suppliers. The establishment of supplier relationship over time aligns with Nunes (2016:148) who found that experience and learning the language and business practices of a sourcing country improved business relationships with suppliers. In addition, some small clothing and textile retailers made use of loyalty buying as suggested by Faes and
Matthyssens (2009:246). Being able to form these informal relationships meant that these small clothing and textile retailers could secure supply of items, and even be given a price discount:

'But when you have figured it out, you have built key relationships you figure out your own way to communicate and get it done.' [B4, Male, Owner]

'And it is also strengthening those relationships so that the more you buy from them the cheaper the costs are.' [B10, Female, Owner]

\section{Exchange rate fluctuation buffers}

Most of the participants managed exchange rate fluctuations by taking the knock in their profit margins either proactively or reactively. Although Jain (2013:26) and Young (2016:4) advocate for the use of hedging as a possible management approach to reduce erosion of purchase price and to ensure that the profit margins are not impacted, none of the small clothing and textile retailers made use of this approach. This is in part because of the additional costs associated with hedging and that most of the small retail owners did not view exchange rates fluctuations as a problem until recently:

'... in the past few years there was a lot of stability, I think the instability is coming only now, for the past few years. And obviously if you take that cover it is an additional cost....' [B11, Female, Owner]

'... so if you are using a, a, a dollar based (what is it?) pricing we would always factor like fluctuations.' [B12, Female, Co-owner]

\section{Dual transportation}

Dual transportation requires the small retail owner to split orders into batches and transport them separately. This is to avoid the possibility of total loss or delay of delivery from the supplier should anything happen (Micheli et al. 2014:123). Only one small retail owner used dual transportation as a supply risk management approach, while two others used it to avoid having to travel with excess luggage:

'... have figured out a way to say I am going to bring in things. So I am not going to bring in a whole container at once, I am going to break it up into pieces to minimise the risk.' [B4, Male, Owner]

'... flight, it gives me $30 \mathrm{~kg}$, and if I buy more stuff at times when they are bargains, I can post my stuff.' [B8, Female, Owner]

\section{Communication and cultural barriers management}

Misunderstandings in language and culture make it difficult for buyers and suppliers to transact successfully (Jiang \& Tian 2009:19; Oke et al. 2009:158). In this study, findings show that small retail owners opted to counter communication and cultural barriers using translation applications and making use of a local who was usually a friend or family member to help facilitate the transactions with suppliers. Over time, some of the small clothing and textile retailers learnt the language. Improved communication between the small retailer and the suppliers helped in securing the supply and allowed for better negotiations:

'... on my second visit, I downloaded an APP, Google translator, where I actually type in English and it would translate it into their language [Turkish].' [B6, Female, Owner] 
'I go there [fabric market] I would go with someone who has basically stayed in Ghana, and they would do most of the talking for me and the explaining.' [B6, Female, Owner]

'... now you ... we even know the language here and there ... and you say bye in Turkish and they like you even more because they [suppliers] know you are trying.' [B9, Female, Owner]

'So, learning the lingo has helped me cause then I start talking like them, I start dressing up like them as well ....' [B10, Female, Owner]

\section{Conclusion}

\section{Summary of findings and theoretical implications}

The aim of the study was to explore the supply risks that small clothing and textile retailers in Gauteng encounter as a result of global sourcing and to determine how they identify and manage these supply risks. The first research question focused on understanding the factors that influence why small clothing and textile retailers engage in global sourcing activities. A detailed literature review was conducted to identify some of the possible influencing factors for global sourcing. The factors identified in the literature review aligned with those found in this study. These were lower cost and higher quality of products in sourcing countries, more variety and limited to no local supply of sourced items. One new emerging factor not identified from the literature was small clothing and textiles retail owners' familiarisation with the sourcing country. This was usually either because the small retail owner travelled extensively there for other business purposes or even sourcing activities, had friends or family living in those countries or was originally from there but currently lived in South Africa. The findings indicate that the influencing factors for small clothing and textile retailers to engage in global sourcing are similar, regardless of business size.

The second research question focused on exploring what supply risks were encountered by these small clothing and textile retailers because of opting to source globally. Findings indicate that small clothing and textile retailers have an awareness of possible supply risks. In line with the supply risks identified in the literature review, this study found that small clothing and textile retailers encountered fluctuating exchange rate risks as most retailers sourced in countries that priced using the US dollar. In addition, communication and cultural barriers and costly and complicated logistics were mostly challenges with high customs costs and high cost of travel to and within the sourcing country. Other supply risks highlighted by the participants included supplier reliability in terms of quality, stock unavailability and delayed delivery lead times, political volatility both locally and in their sourcing countries and adverse environmental conditions in the sourcing country.

The third research question focused on what risk identification approaches were used by the small clothing and textile retailers in identifying supply risks. Although some of the risk identification approaches available in literature require rigour and resource commitments, some of the small clothing and textile retailers seem to be using some approaches informally in identifying supply risks. The approaches used include quality checks, which could be formalised through risk checklists and catalogues, landscape analyses that focused on some elements of the PESTEL analysis and supplier pre-buying review.

The final research question focused on exploring the management approaches used by these small clothing and textile retailers in addressing the identified supply risks. Most of the management approaches identified from the literature review were cited as being used by these small clothing and textile retailers. However, this was done informally at the sole discretion of the owner and not on a frequent basis. These management approaches identified both from the literature and the study included sourcing from multiple partners, reduction of the probability of risks, dual transportation of goods, local sourcing where supplier was not able to meet delivery and another local retailer who had the required item and the building and management of informal supplier relationships. Only one small retail owner used contracts to formalise supplier relationships, whereas all others did this informally through loyalty sourcing among other things.

The study contributes to knowledge in two ways. Firstly, it confirms the similarities between findings from international studies and this one, which is based in the South African context. These findings include the similarities in the supply risks encountered by businesses, regardless of size or geographical location. Both these findings further affirm that businesses encounter and will continue to encounter supply risks regardless of their size or location. In addition, this study found similarities in how businesses of varying sizes identify and manage supply risks. Supply risks were identified and managed based on the sole discretion of either the small retail owner as per this study or as per the supply chain manager based on the international studies done. Secondly, this study identified a new influencing factor to global sourcing. This factor is ease of access to the market, which entailed small clothing and textile retailers electing to source from a specific country purely based on their familiarity with the country. This familiarity could be either that they were originally from that country or that they have local contacts in the form of close friends and family.

\section{Managerial implications}

This study indicates that there are several influencing factors that have resulted in small clothing and textile retailers sourcing globally. Consequently, many of them have been exposed to supply risks. Given the above, this study's findings provide small clothing and textile retail owners with two key insights. Firstly, it notes the supply risks known and identified by each of the small clothing and textile retail owners. Secondly, it shares the supply risks encountered by the other small retailers sourcing in similar and different 
countries. Both these insights could be useful for small retail owners in broadening their awareness on the supply risks in their current and potential sourcing countries. This may also help to reduce the time and other resources that they may have had to invest in identifying these risks on their own. In addition, this study found that although aware of supply risks, none of the small clothing and textile retailers had formal risk identification and assessment approaches in place. However, even in the absence of these formal approaches, some of the small clothing and textile retailers have managed to find ways to address these supply risks. Thus, there is no strong evidence to confine small clothing and textile retailers to set up any formal approaches for identifying and managing supply risks. Instead, several of the informal approaches could be used. Some of the informal risk identifications from this study include random product quality checks and landscape analyses. The benefit to the small retailer of these findings is that there is no need to invest time and money resources in trying to find these informal approaches. Knowledge of these informal approaches could allow the small clothing and textile retailers to use resources for other purposes or finding additional informal approaches. The informal risk management approaches found include informal supplier relationship management and exchange rate buffer creation.

\section{Limitations of this study and suggestions for future research}

In this study, several limitations were noted that could provide areas for future research. Firstly, this study only focused on small clothing and textile retailers in the clothing and textile industry. A similar study exploring small businesses in a different industry engaged in global sourcing, which do not contend with the same challenges and weaknesses faced by the clothing and textile industry, may be particularly helpful. Findings will help to determine whether policymakers should introduce generic enabling solutions for small businesses that source globally or whether they may have to tailor solutions per industry. Secondly, under SCRMP, this study only focused on risk identification and management approaches and not assessment. It may be useful to small clothing and textile retailers if the risk assessment approaches were explored. This may help them in better understanding how to quantify the likelihood and impacts of supply risks, allowing them to determine which supply risks to address and commit their limited resources in terms of time and money on (Smit 2012:182). Thirdly, in this study across all the small clothing and textile retailers interviewed, none had more than 10 employees. In addition, because the small retail owner did all the sourcing activities, they also identified and managed supply risks informally and at their personal discretion. A similar study should be done on small clothing and textile retailers with at least 10 employees who directly engage in the sourcing activities. This may shed light on whether the small retailer owners still choose to have informal supply risk identification and management approaches and allow their employees to address them at their sole discretion. Global sourcing provides benefits to businesses and their local customer base. However, it also still exposes them to supply risks that need to be proactively identified and managed by the business owner or supply chain manager.

\section{Acknowledgements Competing interests}

The authors declare that they have no financial or personal relationships that may have inappropriately influenced them in writing this article.

\section{Authors' contributions}

This article is based on the MPhil dissertation of K.M. who was the main researcher. W.N. assisted as a supervisor with the conceptualisation, literature review, research instrument and review of the draft manuscript. T.K. provided methodological and technical guidance.

\section{References}

Abe, M. \& Ye, L., 2013, 'Building resilient supply chains against natural disasters: The cases of Japan and Thailand', Global Business Review 14(4), 567-586. https://doi. org/10.1177/0972150913501606

Adams, J.H., Khoja, F.M. \& Kauffman, R., 2012, 'An empirical study of buyersupplier relationships within small business organizations', Journal of Small Business Management50(1),20-40.https://doi.org/10.1111/j.1540-627X.2011. 00342. $\mathrm{X}$

Ates, A., Garengo, P., Cocca, P. \& Bititci, U., 2013, 'The development of SME managerial practice for effective performance management', Journal of Small Business and Enterprise Development 20(1), 28-54. https://doi.org/10.1108/14626001311 298402

Badenhorst-Weiss, J.A. \& Waugh, B.J., 2014, 'Business environmental factors affecting South Africa's supply chains and economic growth and development', Problems and Perspectives in Management 12(4), 238-291.

Baldwin, R.E., 2012, Global supply chains: Why they emerged, why they matter, and where they are going, CEPR Discussion Paper No. DP9103, viewed 17 May 2016, from https://ssrn.com/abstract=2153484

Barroso, A., Machado, V.C. \& Machado, V., 2011, Supply chain resilience using the mapping approach, InTech Open Access Publisher, viewed 25 April 2016, from https://www.intechopen.com/books/supply-chain-management/supply-chainresilience-using-the-mapping-approach

Berg, A., Berlemann, B. \& Hedrich, S., 2013., The global sourcing map - Balancing cost, compliance, and capacity, McKinsey \& Company, Germany, viewed 28 April 2017, from http://www.mckinsey.com/ /media/mckinsey/dotcom/client service/retail/articles/the_global_sourcing_map_balancing_cost_compliance _ and_capacity.ashx

Berg, A., Berlemann, B., Hedrich, S., Magnus, K., Mathews, B. \& Russo, B., 2015 Sourcing in a volatile world: The East Africa opportuntity, McKinsey \& Company, viewed 28 April 2017, from https://www.mckinsey.com/ /media/mckinsey/ dotcom/client_service/retail/pdfs/sourcing_in_a_volatile_world_the_east africa_opportunity.ashx

Black, A., 2009, 'Location, automotive policy, and multinational strategy: The position of South Africa in the global industry since 1995', Growth and Change 40(3), 483512. https://doi.org/10.1111/j.1468-2257.2009.00491.x

Borges, M.A., 2015, 'An evaluation of supply chain management in a global perspective', Independent Journal of Management and Production 6(1), 1-29. https://doi.org/10.14807/ijmp.v6i1.211

Brammer, S., Hoejmose, S. \& Millington, A., 2011, 'Managing sustainable global supply chain: Framework and best practices', unpublished working document Ontario, University of Western Ontario, viewed 23 April 2016, from http://nbs.net/wpcontent/uploads/NBS-Executive-Report-Supply-Chains.pdf

Braun, V. \& Clarke, V., 2012, 'Thematic analysis', in H. Cooper (ed.), APA handbook of research methods in psychology, vol. 2, pp. 57-71, American Psychological Association, Washington, DC.

Bruce, M., Daly, L. \& Towers, N., 2004, 'Lean or agile: A solution for supply chain management in the textiles and clothing industry?', International Journal of Operations \& Production Management 24(2), 151-170. https://doi. org/10.1108/01443570410514867

BSI, 2014, Supply chain impact of 2014 Ebola outbreak, London, viewed 16 April 2017, from https://www.bsigroup.com/LocalFiles/Whitepaper\%20Ebola_10.14_7.pdf

Chopra, S. \& Sodhi, M., 2014, 'Reducing the risk of supply chain disruptions', MIT Sloan Management Review 55(3), 73-80. 
Christopher, M., 2011, Logistics and supply chain management, 4th edn., Pearson Education, Great Britain.

Christopher, M. \& Holweg, M., 2011, “'Supply Chain 2.0”: Managing supply chains in the era of turbulence', International Journal of Physical Distribution \& Logistic Management 41(1), 63-82. https://doi.org/10.1108/09600031111101439

Christopher, M., Mena, C., Khan, O. \& Yurt, O., 2011, 'Approaches to managing global sourcing risk', Supply Chain Management: An International Journal 16(2), 67-81. https://doi.org/10.1108/13598541111115338

CIPS, 2013, 'Global vs. local sourcing', in CIPS (ed.), pp. 1-4, London, viewed 01 May 2016, from https://www.cips.org/Documents/Knowledge/Procurement-Topicsand-Skills/13-SRM-and-SC-Management/Global-Supply-Chains/Global_vs_Local_ Sourcing.pdf

Colicchia, C. \& Strozzi, F., 2012, 'Supply chain risk management: A new methodology for a systematic literature review', Supply Chain Management: An International Journal 17(4), 403-418. https://doi.org/10.1108/13598541211246558

Deane, J., Craighead, C. \& Ragsdale, C., 2009, 'Mitigating environmental and density risk in global sourcing', International Journal of Physical Distribution \& Logistic Management 39(10), 861-883. https://doi.org/10.1108/09600030911011450

Dittmann, J., 2014, 'Managing risk in the global supply chain', viewed 04 April 2016 from http://globalsupplychaininstitute.utk.edu/publications/documents/Risk.pdf

Edwards, L. \& Jenkins, R., 2015, 'The impact of Chinese import penetration on the South African manufacturing sector', The Journal of Development Studies 51(4), 447-463. https://doi.org/10.1080/00220388.2014.983912

Ellegaard, C., 2008, 'Supply risk management in a small company perspective', Supply Chain Management: An International Journal 13(6), 425-434. https://doi. org/10.1108/13598540810905688

Ellis, S.C., Henry, R.M. \& Shockley, J., 2010, 'Buyer perceptions of supply disruption risk: A behavioral view and empirical assessment', Journal of Operation Management 28(1), 34-46. https://doi.org/10.1016/j.jom.2009.07.002

Faertes, D., 2015, 'Reliability of supply chains and business continuity management', Procedia Computer Science 55, 1400-1409. https://doi.org/10.1016/j.procs .2015.07.130

Faes, W. \& Matthyssens, P., 2009, 'Insights into the process of changing sourcing strategies', Journal of Business \& Industrial Marketing 24(3/4), 245-255. https:// doi.org/10.1108/08858620910939796

Falkner, E. \& Hiebl, M., 2015, 'Risk management in SMEs: A systematic review of available evidence', The Journal of Risk Finance 16(2), 122-144. https://doi. org/10.1108/JRF-06-2014-0079

Fang, J., Zhao, L., Fransoo, J. \& Van Woensel, T., 2013, 'Sourcing strategies in supply risk management: An approximate dynamic programming approach', Computers \& Operations Research 40(5), 1371-1382. https://doi.org/10.1016/j.cor.2012. 08.016

Gheibi, S., Kazaz, B. \& Webster, S., 2016, Global sourcing under exchange-rate uncertainty, School of Management Syracuse University, New York.

Groepe, F., 2015, 'The role of small business in the economy', in The role of business in local government and local economic development, pp. 1-12, George, South Africa, viewed 09 October 2015, from https://www.resbank.co.za/Lists/Speeches/ Attachments/452/Role\%20of\%20small\%20business\%202015\%20.pdf

Guest, G., Bunce, A. \& Johnson, L., 2006, 'How many interviews are enough? An experiment with data saturation and variability', Field Methods 18(1), 59-82. https://doi.org/10.1177/1525822X05279903

Halldórsson, Á. \& Kovács, G., 2010, 'The sustainable agenda and energy efficiency: Logistics solutions and supply chains in times of climate change', International Journal of Physical Distribution \& Logistics Management 40(1/2), 5-13. https:// doi.org/10.1108/09600031011018019

Hendry, L., Sayed, M. \& Zorini, M., 2015, 'Local buying: The easy answer for sustainable sourcing', viewed 24 May 2016, from https://www.researchgate.net/profile/ Maysara_Sayed/publication/283855968_Local_Buying_The_easy_answer_for_ Sustainable_Sourcing/links/5648ee4a08ae9f9c13ebba1e.pdf

Ho, W., Zheng, T., Yildiz, H. \& Talluri, S., 2015, 'ClSupply chain risk management: A literature review', International Journal of Production Research 53(16), 50315069. https://doi.org/10.1080/00207543.2015.1030467

Hoffmann, P., Schiele, H. \& Krabbendam, K., 2013, 'Uncertainty, supply risk management and their impact on performance', Journal of Purchasing and Supply Management 19(3), 199-211. https://doi.org/10.1016/j.pursup.2013.06.002

Holweg, M., Reichhart, A. \& Hong, E., 2011, 'On risk and cost in global sourcing', International Journal of Production Economics 131(1), 333-341. https://doi. org/10.1016/j.ijpe.2010.04.003

Hopkin, P., 2017, Fundamentals of risk management: Understanding, evaluating and implementing effective risk management, 4th edn., Kogan Page Publishers, London, United Kingdom.

Jain, A., 2013, 'Forex risk management: Ways for succeeding in turbulent economic times', International Journal of Emerging Research in Management \& Technology 2(1), 26-30.

Jain, N., Girotra, K. \& Netessine, S., 2014, 'Managing global sourcing: Inventory performance', Management Science 60(5), 1202-1222. https://doi.org/10.1287/ mnsc.2013.1816

Jia, F., Lamming, R., Sartor, M., Orzes, G. \& Nassimbeni, G., 2014, 'Global purchasing strategy and international purchasing offices: Evidence from case studies', International Journal of Production Economics 154, 284-298. https://doi. org/10.1016/j.ijpe.2013.09.007

Jiang, C. \& Tian, Y., 2009, 'Problems and challenges of global sourcing: A study of Chinese manufacturing enterprises', master's thesis, Jonkoping University, viewe 12 March 2017, from www.diva-portal.org/smash/get/diva2:318924/fulltext01
Kırılmaz, O. \& Erol, S., 2017, 'A proactive approach to supply chain risk management: Shifting orders among suppliers to mitigate the supply side risks', Journal of Purchasing and Supply Management 23(1), 54-65. https://doi.org/10.1016/j. Purchasing and Supply
pursup.2016.04.002

Kumar, S., Himes, K. \& Kritzer, C., 2014, 'Risk assessment and operational approaches to managing risk in global supply chains', Journal of Manufacturing Technology Management 25(6), 873-890. https://doi.org/10.1108/JMTM-04-2012-0044

Kunene, T., 2008, 'A critical analysis of entrepreneurial and business skills in SMEs in the textile and clothing industry in Johannesburg, South Africa', pp. 1-268, viewed 15 May 2016, from http://www.repository.up.ac.za/bitstream/handle/2263 /24173/Complete. pdf?sequence=10

Kunreuther, H. \& Pauly, M., 2014, 'Role of deliberative thinking and emotions in insurance decision making: An experimental study', viewed 20 April 2016, from https://pdfs.semanticscholar.org/8bc0/eddad 9705 b6 bac 9 b6e 24018 14d5e3e8245f4.pdf

Lavastre, O., Gunasekaran, A. \& Spalanzani, A., 2012, 'Supply chain risk management in French companies', Decision Support Systems 52(4), 828-838. https://doi. org/10.1016/j.dss.2011.11.017

Lockamy, A., 2014, 'Assessing disaster risks in supply chains', Industrial Management \& Data Systems 114(5), 755-777. https://doi.org/10.1108/IMDS-11-2013-0477

Maje, M. \& Sunjka, B., 2014, 'The application of soft systems methodology to supply chain risk management small and medium enterprises', viewed $30 \mathrm{Apri}$ 2017, from https://www.saiie.co.za/assets/saiie26/2014/Conference\%20 2014\%20Proceedings.pdf

Manuj, I., 2013, 'Risk management in global sourcing: Comparing the business world and the academic world', Transportation Journal 52(1), 81-107, viewed 25 March 2016, from http://search.ebscohost.com/login.aspx?direct=true\&db=bth\&AN=85 $112514 \&$ site $=$ ehost-live \&scope=site

Manuj, I. \& Mentzer, J., 2008, 'Global supply chain risk management', Journal of Business Logistics 29(1), 133-155. https://doi.org/10.1002/j.2158-1592.2008. tb00072.x

Mehrjoo, M. \& Pasek, Z., 2016, 'Risk assessment for the supply chain of fast fashion apparel industry: A system dynamics framework', International Journal of Production Research 54(1), 28-48. https://doi.org/10.1080/00207543.2014.997405

Micheli, G., Mogre, R. \& Perego, A., 2014, 'How to choose mitigation measures for supply chain risks', International Journal of Production Research 52(1), 117-129. https://doi.org/10.1080/00207543.2013.828170

Mndzebele, M., 2013, An assessment of supply chain risk management in Africa: The case of UNKI Platinum Mine in Zimbabwe, Gordon Institute of Business University of Pretoria, Pretoria, viewed 17 April 2017, from http://hdl.handle. net/2263/40577.

Muhos, M., Wang, L. \& Kess, P., 2012, 'Experiences of Finnish SMEs sourcing from China', China-USA Business Review 11(7), 958-968.

Murray-Webster, R., 2010, Management of risk: Guidance for practitioners, 3rd edn., The Stationery Office, Norwich, United Kingdom.

Nunes, M., 2016, 'Motivations, risks, barriers, and results associated with the adoption of global sourcing by Brazilian companies: A case-based study', Brazilian Business Review (English Edition) 13(2), 135-157. https://doi.org/10.15728/ bbr.2016.13.2.6

Oke, A., Maltz, A. \& Christiansen, A., 2009, 'Criteria for sourcing from developing countries', Strategic Outsourcing: An International Journal 2(2), 145-164. https:// doi.org/10.1108/17538290910973367

Olson, D. \& Wu, D., 2010, 'A review of enterprise risk management in supply chain', Kybernetes 39(5), 694-706. https://doi.org/10.1108/03684921011043198

Palaniappan, P.K., 2014, 'Risk assessment and management in supply chain', Globa Journal of Research In Engineering 14(2), 18-33.

Palinkas, L., Horwitz, S., Green, C., Wisdom, J., Duan, N. \& Hoagwood, K., 2015, 'Purposeful sampling for qualitative data collection and analysis in mixed method implementation research', Administration and Policy in Mental Health and Mental Health Services Research 42(5), 533-544. https://doi.org/10.1007/s10488-0130528-y

Peace, C., 2013, 'Supply chain-related risk management', paper presented at Supply Chain Collaboration - The Way of the Future Conference, Tauranga, NZ, viewed 18 March 2016, from https://www.riskmgmt.co.nz/fileadmin/documents/ March 2016, from https://www.riskmg

Peter, C., 2016, 'Managing risk and building resilient organisations in a riskier world', Journal of Organizational Effectiveness: People and Performance 3(3), 323-331. Journal of Organizational Effectiveness: Peop/
https://doi.org/10.1108/JOEPP-07-2016-0044

Pfohl, H., Köhler, H. \& Thomas, D., 2010, 'State of the art in supply chain risk management research: Empirical and conceptual findings and a roadmap for the
implementation in practice', Logistics Research 2(1), 33-44. https://doi. implementation in practice',
org/10.1007/s12159-010-0023-8

Plano Clark, V. \& Creswell, J., 2015, Understanding research: A consumer's guide, 2nd edn., Pearson Higher Education, Upper Saddle River, NJ.

Polit, D. \& Beck, C., 2012, Nursing research: Generating and assessing evidence for nursing practice, 9th edn., Lippincott Williams \& Wilkins, Philadelphia, PA.

Ray, P. \& Jenamani, M., 2016, 'Sourcing decision under disruption risk with supply and demand uncertainty: A newsvendor approach', Annals of Operations Research 237(1), 237-262. https://doi.org/10.1007/s10479-014-1649-8

Routroy, S. \& Shankar, A., 2014, 'A study of apparel supply chain risks', IUP Journal of Supply Chain Management 11(2), 52-69.

Saunders, M., Lewis, P. \& Thornhill, A., 2009, Research methods for business students, 5 th edn., Pearson Education, Harlow, United Kingdom. 
Sayed, Z. \& Sunjka, B., 2016, 'Investigating and evaluating the influence of supply chain structure on supply chain risk' South African Journal of Industrial chain structure on supply chain risk', South African Journal
Engineering 27(3), 122-135. https://doi.org/10.7166/27-3-1645

Shen, B., 2014, 'Sustainable fashion supply chain: Lessons from H\&M', Sustainability 6(9), 6236-6249. https://doi.org/10.3390/su6096236

Shenton, A., 2004, 'Strategies for ensuring trustworthiness in qualitative research projects', Education for Information 22(2), 63-75. https://doi.org/10.3233/EFI2004-22201

Sherwin, M.D., Medal, H. \& Lapp, S.A., 2016, 'Proactive cost-effective identification and mitigation of supply delay risks in a low volume high value supply chain using fault-tree analysis', International Journal of Production Economics 175, 153-163. https://doi.org/10.1016/j.ijpe.2016.02.001

Smit, Y., 2012, A structured approach to risk management for South African SMEs, Cape Peninsula University of Technology, viewed 11 May 2017, from http://hdl. handle.net/11189/651

Sodhi, M., Son, B. \& Tang, C., 2012, 'Researchers' perspectives on supply chain risk management', Production and Operations Management 21(1), 1-13. https://doi. $\mathrm{org} / 10.1111 / \mathrm{j} .1937-5956.2011 .01251 . x$

South African Governement, 1996, South African National Small Business Act, No. 102 of 1996, viewed 06 June 2016, from https://www.thedti.gov.za/sme development/docs/act.pdf

Srinivasan, M., Mukherjee, D. \& Gaur, A.S., 2011, 'Buyer-supplier partnership quality and supply chain performance: Moderating role of risks, and environmental uncertainty', European Management Journal 29(4), 260-271. https://doi. org/10.1016/j.emj.2011.02.004

Steven, A., Dong, Y. \& Corsi, T., 2014, 'Global sourcing and quality recalls: An empirical study of outsourcing-supplier concentration-product recalls linkages', Journal of Operations Management 32(5), 241-253. https://doi.org/10.1016/j.jom.2014 .04 .003

Su, J. \& Gargeya, V., 2012, 'Strategic sourcing, sourcing capability and firm performance in the US textile and apparel industry', Strategic Outsourcing: An International Journal 5(2), 145-165. https://doi.org/10.1108/17538291211257592

Sunjka, B. \& Emwanu, B., 2013, 'A conceptual framework for the analysis of supply chain risk management in small and medium manufacturing enterprises in South Africa', paper presented at SAlIE25 Proceedings, Stellenbosch, viewed 30 April 2017, from http://conferences.sun.ac.za/index.php/saiie25/SAllE25/paper/ view/640/256
Thun, J., Drüke, M. \& Hoenig, D., 2011, 'Managing uncertainty: An empirical analysis of supply chain risk management in small and medium-sized enterprises', International Journal of Production Research 49(18), 5511-5525. https://doi.org/ International Journal of Production

Timm, S., 2013, 'South Africa's poor performance in entrepreneurship events', Mail \& Guardian, 29 November, viewed 07 May 2016, from http://mg.co.za/article/201311-29-00-south-africas-poor-performance-in-entrepreneurship-events

Towers, N. \& Song, Y., 2010, 'Assessing the future challenges in strategic sourcing commodity from China: A case-study analysis', Asia Pacific Business Review 16(4), 527-544. https://doi.org/10.1080/13602380903068071

Tummala, R. \& Schoenherr, T., 2011, 'Assessing and managing risks using the supply chain risk management process (SCRMP)', Supply Chain Management: An International Journal 16(6), 474-483. https://doi.org/10.1108/13598541111 171165

Turker, D. \& Altuntas, C., 2014, 'Sustainable supply chain management in the fast fashion industry: An analysis of corporate reports', European Management Journal 32(5), 837-849. https://doi.org/10.1016/j.emj.2014.02.001

Verbano, C. \& Venturini, K., 2013, 'Managing risks in SMEs: A literature review and research agenda', Journal of Technology Management \& Innovation 8(3), 186197. https://doi.org/10.4067/S0718-27242013000400017

Vilko, J., 2012, Approaches to supply chain risk management: Identification, analysis and control, Lappeenranta University of Technology Digipaino, Lappeenranta, Finland.

Wieland, A. \& Wallenburg, C., 2012, 'Dealing with supply chain risks: Linking risk management practices and strategies to performance', International Journal of Physical Distribution \& Logistics Management 42(10), 887-905. https://doi. org/10.1108/09600031211281411

Williams, M., 2013, 'South Africa's carmakers suffer a month of strike disruption in supply chai', viewed 16 April 2017, from http://automotivelogistics.media/news/ south-africas-carmakers-suffer-a-month-of-strike-disruption-in-supply-chain

Yang, Z., 2014, 'The impact of the emergence of China's economy on South Africa', Master of Arts, Universite Laval, Quebec, Canada, viewed 09 April 2016, from http://www.theses.ulaval.ca/2014/31088/31088.pdf

Young, J., 2016, 'Managing risk in global supply chains: The changing role of corporate treasury', viewed 05 February 2017, from https://financial.thomsonreuters.com/ content/dam/openweb/documents/pdf/financial/managing-risk-in-globalsupply-chains.pdf 